\title{
Silver nanoparticle dissolution in the presence of ligands and of hydrogen peroxide
} Laura Sigg* and Ursula Lindauer Eawag, Swiss Federal Institute of Aquatic Science and Technology, $\mathrm{CH}-8600$ Duebendorf, Switzerland

\section{Abstract}

Dissolution of silver nanoparticles (AgNP with carbonate or citrate coating, total Ag $1-5$ $\mu \mathrm{M})$ was examined in the presence of the ligands cysteine, chloride and fulvic acids and of the oxidant hydrogen peroxide $\left(\mathrm{H}_{2} \mathrm{O}_{2}\right)$ at low concentrations at $\mathrm{pH}$ 7.5. Dissolved $\mathrm{Ag}$ was separated from AgNP by ultrafiltration. Cysteine in the concentration range $0.2-5 \mu \mathrm{M}$ resulted in an initial increase of dissolved Ag within few hours. Chloride (up to $0.1 \mathrm{mM}$ ) and fulvic acids (up to $15 \mathrm{mg} \mathrm{L}^{-1}$ ) had little effect on the dissolution of AgNP within hours to days. In contrast, very rapid dissolution within $1-2 \mathrm{~h}$ of both carbonate and citrate coated $\mathrm{AgNP}$ was observed in the presence of $\mathrm{H}_{2} \mathrm{O}_{2}$ in the concentration range $0.1-10 \mu \mathrm{M}$, under dark or light conditions. The high efficiency of $\mathrm{H}_{2} \mathrm{O}_{2}$ in dissolving AgNP is likely to be of importance in toxic effects of $\mathrm{AgNP}$ to algae, as $\mathrm{H}_{2} \mathrm{O}_{2}$ is produced and released into solution by algae.

\section{Capsule}

Dissolution of silver nanoparticles in the presence of cysteine, chloride and fulvic acids and of hydrogen peroxide is an important process influencing toxicity to aquatic organisms.

Keywords: silver nanoparticles, dissolution, cysteine, chloride, fulvic acids, hydrogen peroxide

*Corresponding author, email: laura.sigg@eawag.ch, Tel. +41 587655494

This document is the accepted manuscript version of the following article:

Sigg, L., \& Lindauer, U. (2015). Silver nanoparticle dissolution in the presence of 1igands and of hydrogen peroxide. Environmental Pollution, 206, 582-587. https://doi .org/10.1016/j . envpo1.2015.08.017 
29

30

31

32

3

34

35

36

\section{Graphical abstract} toxicity experiments;

- Effects of cysteine on AgNP dissolution;

- Rapid dissolution of AgNP with hydrogen peroxide;

5

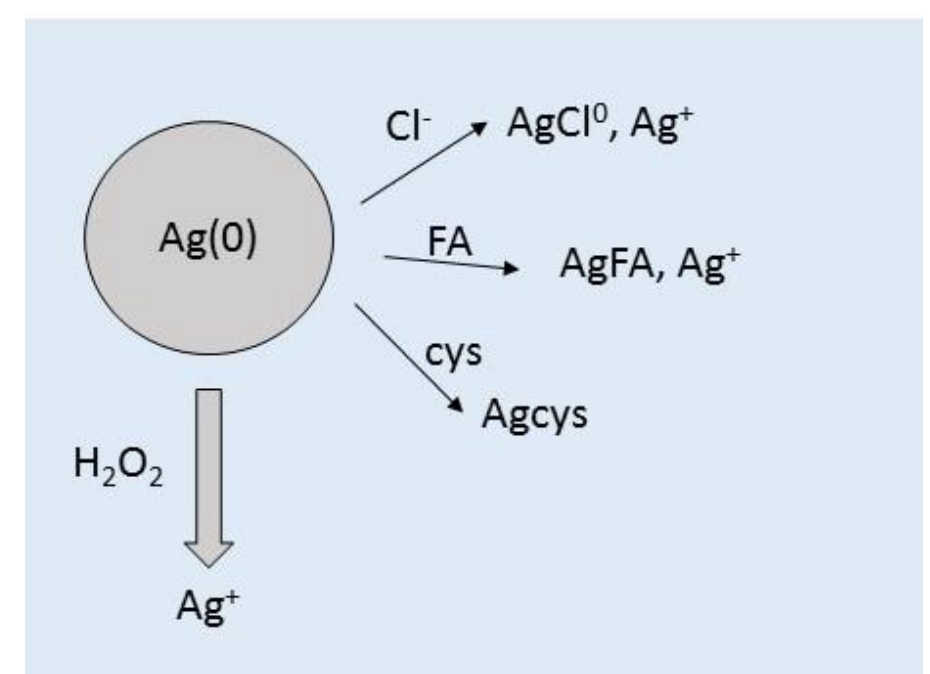

37

- Dissolution of silver nanoparticles under relevant conditions for natural waters and for

- Weak effects of chloride and fulvic acids on AgNP dissolution;

- Relevance of dissolution with $\mathrm{H}_{2} \mathrm{O}_{2}$ for toxicity of AgNP to algae. 


\section{Introduction}

Dissolution of silver nanoparticles (AgNP) is an important process determining both their effects to organisms and their fate in aqueous environments (Levard et al., 2012; Lowry et al., 2012; Behra et al., 2013; Sigg et al., 2014). Dissolved $\mathrm{Ag}^{+}$ions are known to be toxic to various aquatic organisms, including bacteria, algae and fish (Bury et al., 1999; Bury and Wood, 1999; Hiriart-Baer et al., 2006; Navarro et al., 2008; Xiu et al., 2011). For toxicity assessment of silver nanoparticles, it is thus essential to take into account the dissolution reactions in order to distinguish between ion and nanoparticle effects. Toxic effects of silver nanoparticles have already been shown in various organisms to be mostly due to the effects of silver ions which are released into solution from $\mathrm{AgNP}$ as a result of interactions with exposure media and with the organisms (Navarro et al., 2008; Xiu et al., 2011; Yang et al., 2012; Navarro et al., 2015). The processes influencing dissolution of silver nanoparticles need thus to be investigated in natural waters as well as in experimental media.

Dissolution of $\operatorname{AgNP}$, which includes an oxidation step of $\operatorname{Ag}(0)$ to $\operatorname{Ag}(\mathrm{I})$, is expected to depend on the presence of oxygen and other oxidants, on $\mathrm{pH}$ and on available ligands for $\operatorname{Ag}(\mathrm{I})$ in solution (Liu and Hurt, 2010; Ma et al., 2011; Liu et al., 2010; Gondikas et al., 2012). AgNP dissolution has been shown to be more efficient and faster at lower $\mathrm{pH}$ (Liu et al., 2010). Strongly binding ligands for $\mathrm{Ag}(\mathrm{I})$ include mostly sulfide and thiol ligands (e.g. cysteine), whereas chloride forms only weaker complexes. Binding of silver to humic or fulvic acids is expected to be stronger to the few thiol groups than to the more abundant carboxyl, hydroxyl and amino groups (Chen et al., 2012). Thiol ligands may accelerate the dissolution process of AgNP, as shown for high cysteine concentrations (Gondikas et al., 2012). However, binding of inorganic sulfide to AgNP has been shown to lead to the rapid formation of a solid silver sulfide solid phase with very low solubility (Kaegi et al., 2011). Effects of chloride have to be carefully considered, as depending on the concentration, formation of solid $\mathrm{AgCl}(\mathrm{s})$ or of dissolved complexes with $\mathrm{Ag}(\mathrm{I})$ may occur. Furthermore, dissolution of AgNP is also dependent on the various coatings used for colloidal stability and on the nanoparticle size (Ma et al., 2011). Dissolution of $\mathrm{AgNP}$ by $\mathrm{H}_{2} \mathrm{O}_{2}$ has been examined in the context of conditions of washing of textiles containing AgNP (Geranio et al., 2009), in which $\mathrm{H}_{2} \mathrm{O}_{2}$ was shown to efficiently increase $\mathrm{Ag}^{+}$release. Reactions of $\mathrm{H}_{2} \mathrm{O}_{2}$ with $\mathrm{AgNP}$ have also been studied in more detail with respect to the reaction kinetics and mechanisms (He et al., 2011; He et al., 2012).

The aim of this study is to examine dissolution of silver nanoparticles under conditions which are relevant for experimental media used in toxicity studies of AgNP to algae and other 
aquatic organisms, as well as for natural freshwaters. Two often used AgNP coatings are considered, namely carbonate and citrate. The effect of some relevant ligands for $\operatorname{Ag}(\mathrm{I})$ is examined, namely chloride, cysteine and fulvic acids, as well as the effect of the oxidant hydrogen peroxide $\left(\mathrm{H}_{2} \mathrm{O}_{2}\right)$ at low concentrations. Hydrogen peroxide is used here as a reactive oxidant at low concentrations, which may also be produced by algae (He et al., 2012a; Pospisil, 2012). The implications of the observed dissolution reactions and of the dissolved Ag concentrations for toxicity experiments are discussed.

\section{Materials and methods}

\section{Materials}

Silver nanoparticles with carbonate or citrate (carb-AgNP and cit-AgNP) coating were obtained from NanoSys GmbH (Wolfhalden, Switzerland) as aqueous suspensions with a nominal concentration of $1 \mathrm{~g} \mathrm{Ag} \mathrm{L}^{-1}$. The same types of nanoparticles have previously been used in several studies in our laboratory (Navarro et al., 2008; Piccapietra et al., 2012a; Piccapietra et al., 2012b). The stock nanoparticle suspensions contained a small fraction of dissolved Ag, which originates from the AgNP production. The average size of the carbAgNP in the stock suspension was $29 \mathrm{~nm}$ and the size of the cit-AgNP $17 \mathrm{~nm}$ (Piccapietra et al., 2012a; Navarro et al. 2015).

MOPS (3-morpholino propanesulfonic acid), $\mathrm{NaCl}$, L-cysteine, $\mathrm{NaOH}$ were purchased from Sigma-Aldrich, $\mathrm{H}_{2} \mathrm{O}_{2}(30 \%)$ from Merck (suprapure chemicals). Fulvic acids (Standard Suwannee River I) were obtained in dry form from the International Humic Substances Society.

All solutions were prepared using nanopure water (Barnstead Nanopure Skan AG). Fulvic acid stock solutions were prepared by adding $5 \mathrm{mg}$ fulvic acid to $100 \mathrm{~mL}$ of MOPS buffer (10 $\mathrm{mM})$. Cysteine solutions were freshly prepared on ice on the day of the experiment. $\mathrm{H}_{2} \mathrm{O}_{2}$ was diluted to the experimental concentrations immediately before start of the experiment.

\section{Experimental design}

AgNP (carbonate or citrate coated) were added to the appropriate medium from stock solutions containing $0.1 \mathrm{~g} \mathrm{~L}^{-1} \mathrm{AgNP}$ to reach a total Ag concentration of $5 \mu \mathrm{M}$ or $1 \mu \mathrm{M}$. Dissolved Ag was measured after various time intervals (minutes to several days) after separation of the nanoparticles by ultrafiltration. All experiments were carried out in solutions 
106 containing $10 \mathrm{mM}$ MOPS as buffer, which were adjusted to $\mathrm{pH}$ 7.5. Ligands (chloride (0.02 -

$1070.1 \mathrm{mM})$, cysteine $(0.2-5 \mu \mathrm{M})$, fulvic acids $\left(8\right.$ or $\left.\left.15 \mathrm{mg} \mathrm{L}^{-1}\right)\right)$, or $\mathrm{H}_{2} \mathrm{O}_{2}(0.1-10 \mu \mathrm{M})$ were

108 added to this buffer. After addition of $\mathrm{AgNP}$, the experimental solutions were thoroughly

109 mixed and kept on a shaker for the duration of the experiment. For experiments under dark

110 conditions, the samples were wrapped in aluminum foil. For experiments under light

111 conditions, the samples were exposed to daylight in the laboratory.

112 A dissolution experiment was also carried out in a conditioned culture medium for algae,

113 which means a medium in which algae had been growing for $24 \mathrm{~h}$ and were removed by

114 centrifugation. The experiment was started in this medium immediately after removing the 115 algae.

116 Samples were taken from the experimental solutions at various time intervals. The first

117 sample (time 0) was taken immediately after mixing and was further treated as quickly as

118 possible. Dissolved Ag was then separated from AgNP by centrifugal ultrafiltration (Amicon

119 Ultra Tubes, cut off $3 \mathrm{kD}$ ). Centrifugation was carried out over 30 or $10 \mathrm{~min}$. The ultrafiltrate

120 was acidified to $0.01 \mathrm{M} \mathrm{HNO}_{3}$. To check for total concentrations, suspensions were digested

121 using $\mathrm{HNO}_{3}(65 \%)$ and $\mathrm{H}_{2} \mathrm{O}_{2}(30 \%)$ in a high-performance microwave unit (mls $\left.1200 \mathrm{Mega}\right)$.

Ag measurements

124 Ag in ultrafiltered solutions or in digested solutions was measured by HR-ICP-MS (Thermo

125 Finnigan Element 2) using the ${ }^{109} \mathrm{Ag}$ isotope. Reference solutions (NIST Standard Reference

126 Material 1640) were used to check for accuracy of the measurements. 


\section{Results}

Dissolution of AgNP in the presence of the ligands cysteine, chloride, fulvic acids and in algae media

132 Dissolution of $\mathrm{Ag}$ from carb-AgNP (total $\mathrm{Ag}=5 \mu \mathrm{M}$ ) in the presence of various

133 concentrations of cysteine is shown as a function of time in Figure 1. The initial dissolved $\mathrm{Ag}$

134 concentration in this medium in the absence of cysteine was $0.1 \mu \mathrm{M}$. An initial increase in

135 dissolved Ag was observed within few hours at the higher cysteine concentrations $(2-5 \mu \mathrm{M})$,

136 but not at the lower added cysteine concentrations $(0.2 ; 0.5 \mu \mathrm{M})$. At all cysteine

137 concentrations, dissolved Ag was decreasing after $24 \mathrm{~h}$ to values below the initial

138 concentration. At the highest used cysteine concentration $(5 \mu \mathrm{M})$, dissolved Ag initially

139 increased to $0.95 \mu \mathrm{M}(19 \%$ of total $\mathrm{Ag})$ after $4 \mathrm{~h}$, before decreasing to less than $0.1 \mu \mathrm{M}$ after

$14024 \mathrm{~h}$. In the case of citrate coated cit-AgNP, all used cysteine concentrations resulted in lower

141 dissolved Ag concentrations than in the absence of cysteine. The dissolved Ag concentrations

142 decreased in the presence of cysteine as a function of time over $24 \mathrm{~h}$ (Figure 2). 


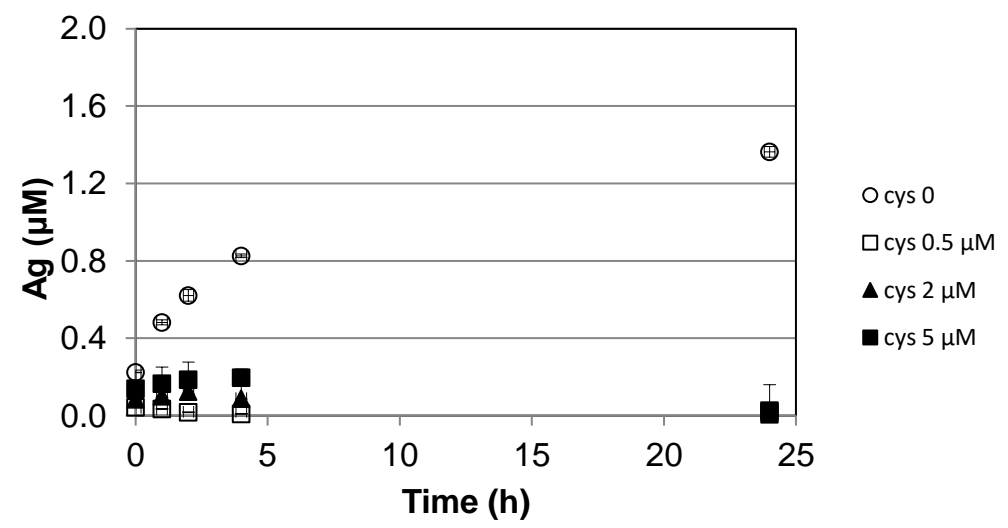
within the symbol size).
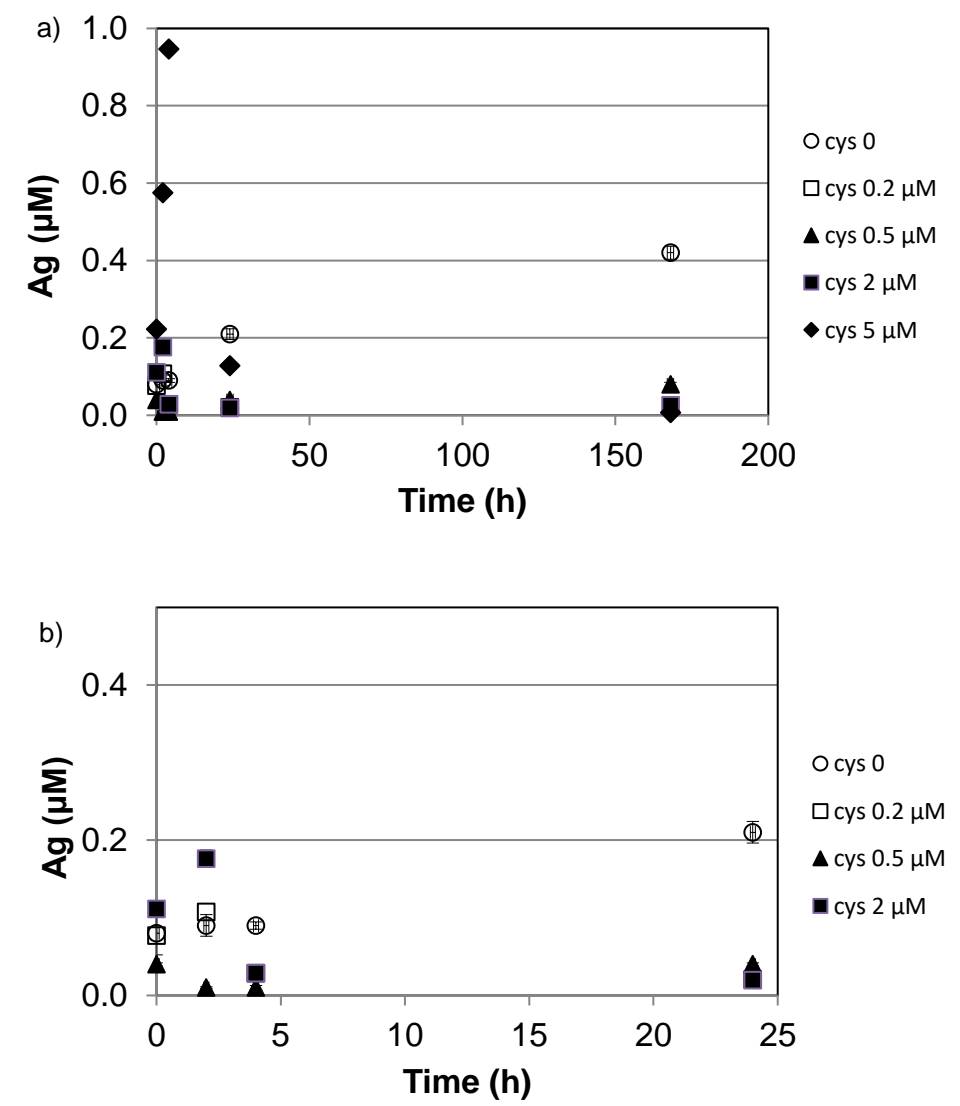
samples are in most cases within the symbol size).

Fig. 1: Dissolved Ag from carbonate $\mathrm{AgNP}$ (total $\mathrm{Ag}=5 \mu \mathrm{M}$ ) in the presence of various cysteine concentrations $(0.2-5 \mu \mathrm{M})$. a) all data over time up to $168 \mathrm{~h})$; b) lower concentrations over time up to $24 \mathrm{~h}$. (error bars based on duplicate samples are in most cases

Fig. 2. Dissolved $\mathrm{Ag}$ from citrate $\mathrm{AgNP}$ (total $\mathrm{Ag}=5 \mu \mathrm{M}$ ) in the presence of various cysteine concentrations $(0.5-5 \mu \mathrm{M})$ as a function of time over $24 \mathrm{~h}$. (error bars based on duplicate 
Addition of chloride up to $0.1 \mathrm{mM}$ only had a slight effect on carb-AgNP dissolution (Figure 3). No significant differences among experimental samples with or without chloride were detected within $24 \mathrm{~h}$, whereas at the highest used $\mathrm{Cl}^{-}$concentration $(0.1 \mathrm{mM})$ an increase in dissolved Ag was observed after $168 \mathrm{~h}$. The highest dissolved Ag concentration was in this case $0.4 \mu \mathrm{M}$ ( $8 \%$ of total $\mathrm{Ag})$. This concentration is below the solubility limit of $\mathrm{AgCl}(\mathrm{s})$ (log $\left.\mathrm{K}_{\mathrm{s} 0}=-9.75\right)$ in the presence of $0.1 \mathrm{mM} \mathrm{Cl}^{-}$.

Addition of fulvic acids ( 8 or $15 \mathrm{mg} \mathrm{L}^{-1}$ ) did not significantly affect dissolution of carb-AgNP over $24 \mathrm{~h}$ (Figure 4). The highest dissolved Ag concentrations reached after $24 \mathrm{~h}$ were about $0.4 \mu \mathrm{M}$ and were similar in the presence or absence of fulvic acids.

No dissolution of carb-AgNP was observed in conditioned culture media, both under light and dark conditions (SI Figure SI 1). The initial dissolved Ag concentration slightly decreased over $24 \mathrm{~h}$ in these media.

Agglomeration of carb-AgNP and of cit-AgNP has been examined under various conditions in other studies (Navarro et al., 2015; Piccapietra et al., 2012b; Topuz et al., 2014). CarbAgNP had average size of $50-53 \mathrm{~nm}$ in the medium $10 \mathrm{mM}$ MOPS at $\mathrm{pH} 7.5$, and the addition of $\mathrm{NaCl}$ in the concentration range $0.02-0.1 \mathrm{mM}$ was not expected to induce any agglomeration, in a similar way as $\mathrm{NaNO}_{3}$ (Piccapietra et al., 2012b). FA in the used concentration range did also not induce agglomeration. Cit-AgNP had also a stable size around $45 \mathrm{~nm}$ at the same ionic strength and $\mathrm{pH}$ 7.5. No size increase was observed upon addition of low $\mathrm{Cl}^{-}$and FA concentrations (Topuz et al., 2014). Addition of cysteine in a similar concentration range did not affect the size of carb-AgNP within $2 \mathrm{~h}$ (Navarro et al., 2008), but led to some increase of the size of cit-AgNP (Navarro et al., 2015).

Fig. 3: Dissolved Ag from carbonate $\mathrm{AgNP}$ (total $\mathrm{Ag}=5 \mu \mathrm{M}$ ) in the presence of chloride $(0.02 ; 0.1 \mathrm{mM})$ as a function of time over $672 \mathrm{~h}(28 \mathrm{~d})$.

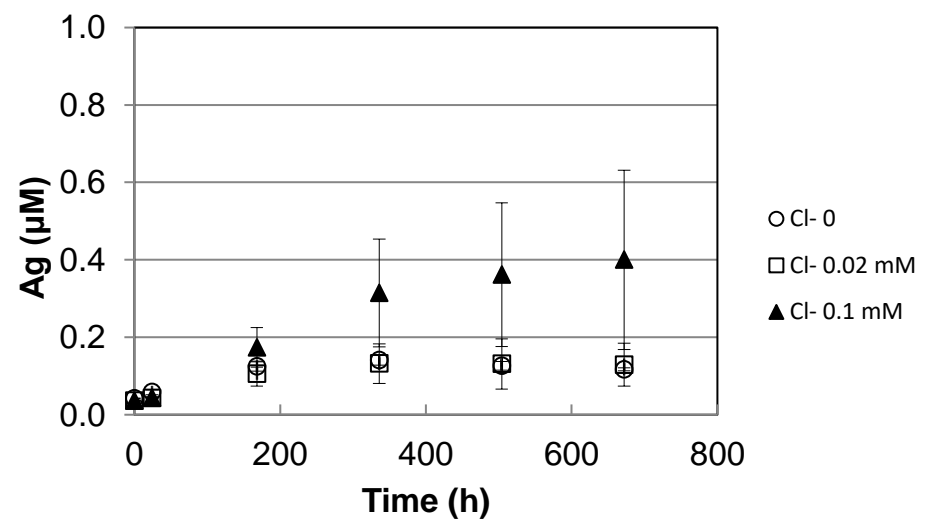


Fig. 4: Dissolved Ag from carbonate AgNP (total $\mathrm{Ag}=5 \mu \mathrm{M}$ ) in the presence of fulvic acids (8 and $15 \mathrm{mg} \mathrm{L}^{-1}$ ) under dark conditions as a function of time over $24 \mathrm{~h}$.

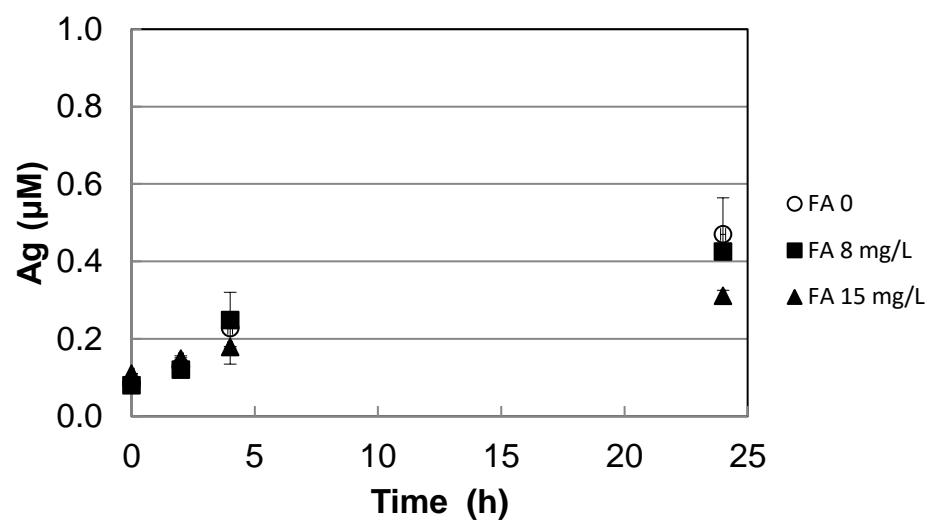

\section{Dissolution of AgNP with $\mathrm{H}_{2} \mathrm{O}_{2}$}

Rapid dissolution of carb-AgNP was observed upon addition of $\mathrm{H}_{2} \mathrm{O}_{2}$ in the concentration range 0.1- $10 \mu \mathrm{M}$, both under dark and light conditions (Figure 5). With an excess of $\mathrm{H}_{2} \mathrm{O}_{2}$ $(10 \mu \mathrm{M})$, carb-AgNP were completely dissolved within about 30 minutes, both under dark and light conditions. The initial measured dissolved Ag value reflected in this case the time required for sampling and separating the suspension and corresponded to dissolved Ag after about 10 - 15 minutes, which was relevant for the very fast reaction under these conditions. At the lower $\mathrm{H}_{2} \mathrm{O}_{2}$ concentrations, the dissolved $\mathrm{Ag}$-concentration continuously increased over $2 \mathrm{~h}$ and reached values of $1.1 \mu \mathrm{M}$ Ag with $0.1 \mu \mathrm{M} \mathrm{H}_{2} \mathrm{O}_{2}$ and $3.4 \mu \mathrm{M}$ Ag with $1 \mu \mathrm{M} \mathrm{H}_{2} \mathrm{O}_{2}$ under light conditions, whereas under dark conditions somewhat lower dissolved Ag were measured. If the dissolved concentrations in absence of $\mathrm{H}_{2} \mathrm{O}_{2}$ were subtracted from the final concentrations, the increase in dissolved $\mathrm{Ag}$ with $\mathrm{H}_{2} \mathrm{O}_{2}$ under dark conditions was $0.26 \mu \mathrm{M}$ with $0.1 \mu \mathrm{M} \mathrm{H}_{2} \mathrm{O}_{2}$ and $2.4 \mu \mathrm{M}$ with $1 \mu \mathrm{M} \mathrm{H}_{2} \mathrm{O}_{2}$. Even the addition of a low concentration of $0.01 \mu \mathrm{M} \mathrm{H}_{2} \mathrm{O}_{2}$ resulted in a detectable increase in dissolved $\mathrm{Ag}$, especially under light conditions (supporting information Figure SI 2).

Using cit-AgNP, similar results for dissolved Ag were obtained upon addition of $\mathrm{H}_{2} \mathrm{O}_{2}$, with a rapid dissolution within $4 \mathrm{~h}$ and close to complete dissolution of $5 \mu \mathrm{M} A g N P$ with $1 \mu \mathrm{M} \mathrm{H}_{2} \mathrm{O}_{2}$ after $4 \mathrm{~h}$, both under light and dark conditions (Figure 6). The difference between light and dark conditions was in this case smaller than this difference for carb-AgNP. 
213

214

215

216

217

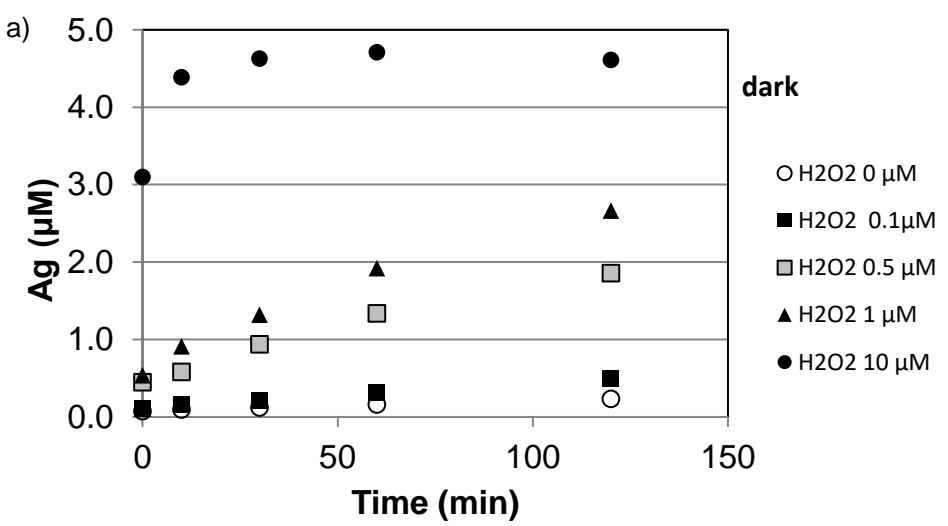

Fig. 5: Dissolved $\mathrm{Ag}$ from carbonate $\mathrm{AgNP}$ (total $\mathrm{Ag}=5 \mu \mathrm{M}$ ) with $\mathrm{H}_{2} \mathrm{O}_{2}(0.1 / 0.5 / 1 / 10 \mu \mathrm{M}$ ) under dark (a) and light conditions (b) as a function of time over 120 min (error bars based on duplicate samples are in most cases within the symbol size).

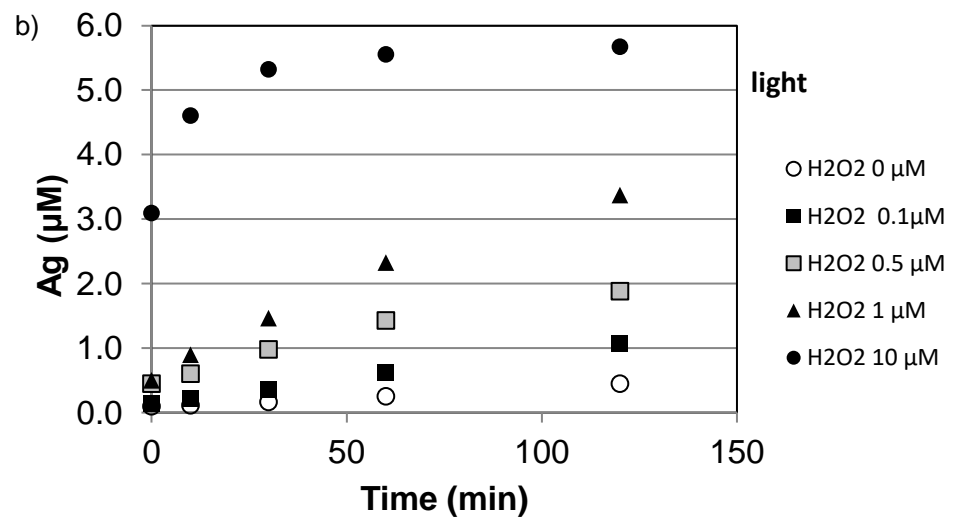

218 
Fig. 6: Dissolved Ag from citrate-AgNP (total $\mathrm{Ag}=5 \mu \mathrm{M}$ ) with $\mathrm{H}_{2} \mathrm{O}_{2}(0.1 / 1 \mu \mathrm{M}$ ) under dark and light conditions as a function of time over $240 \mathrm{~min}$ (error bars based on duplicate samples are in most cases within the symbol size).
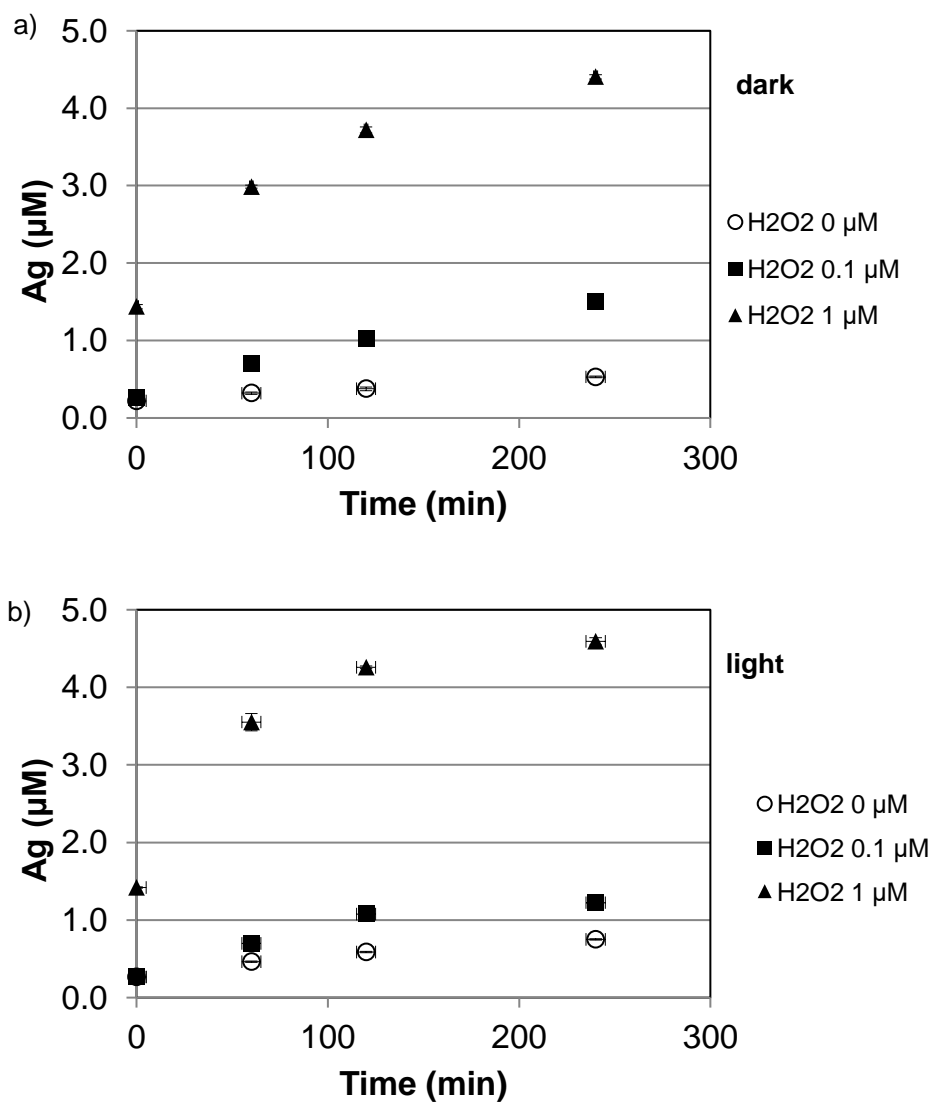

Dissolution rates were calculated by linearization from the first part of the curves of dissolved $\mathrm{Ag}$ versus time for the various $\mathrm{H}_{2} \mathrm{O}_{2}$ concentrations (Figures 5 and 6). In the case of the highest $\mathrm{H}_{2} \mathrm{O}_{2}$ concentration $(10 \mu \mathrm{M})$, a linear dissolution rate could not be calculated because of the very rapid dissolution. These dissolution rates are plotted as a function of the initial $\mathrm{H}_{2} \mathrm{O}_{2}$ concentrations in Figure 7 and illustrate the dependence on $\mathrm{H}_{2} \mathrm{O}_{2}$ concentrations. In the case of carb-AgNP, the dissolution rates were higher in the presence of light, whereas for citAgNP they were nearly identical in the presence or absence of light. The dissolution rates are

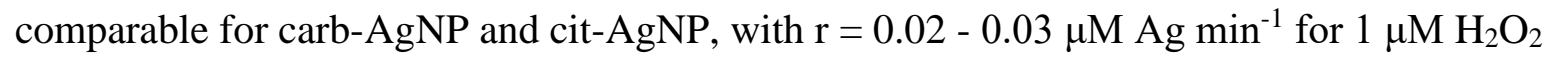
and $5 \mu \mathrm{M}$ AgNP. These dissolution rates can also be related to the surface area of the nanoparticles. Using nanoparticle diameters of $40-50 \mathrm{~nm}$, as obtained for these AgNP in similar media, the surface area of one nanoparticle is $5.03-7.85 \times 10^{-15} \mathrm{~m}^{2}$, and the total surface area in a suspension of $5 \mu \mathrm{M}$ AgNP is $7.7 \times 10^{-3} \mathrm{~m}^{2} \mathrm{~L}^{-1}$ for $\mathrm{d}=40 \mathrm{~nm}$ and $6.1 \times 10^{-3} \mathrm{~m}^{2}$ 
$\mathrm{L}^{-1}$ for $\mathrm{d}=50 \mathrm{~nm}$. The resulting dissolution rates are then for $\mathrm{r}=0.02 \mu \mathrm{M} \mathrm{Ag} \min ^{-1} 2.6 \times 10^{-6}-$ $3.3 \times 10^{-6} \mathrm{~mol} \mathrm{Ag} \mathrm{m}^{-2} \mathrm{~min}^{-1}$ and for $\mathrm{r}=0.03 \mu \mathrm{M} \mathrm{Ag} \mathrm{min}^{-1} 3.9 \times 10^{-6}-4.9 \times 10^{-6} \mathrm{~mol} \mathrm{Ag} \mathrm{m}^{-2}$ $\min ^{-1}$.

Fig. 7. Dissolution rates $\left(\mu \mathrm{M} \mathrm{Ag} \min ^{-1}\right)$ for carb-AgNP and cit-AgNP as a function of $\mathrm{H}_{2} \mathrm{O}_{2}$ $(\mu \mathrm{M})$.

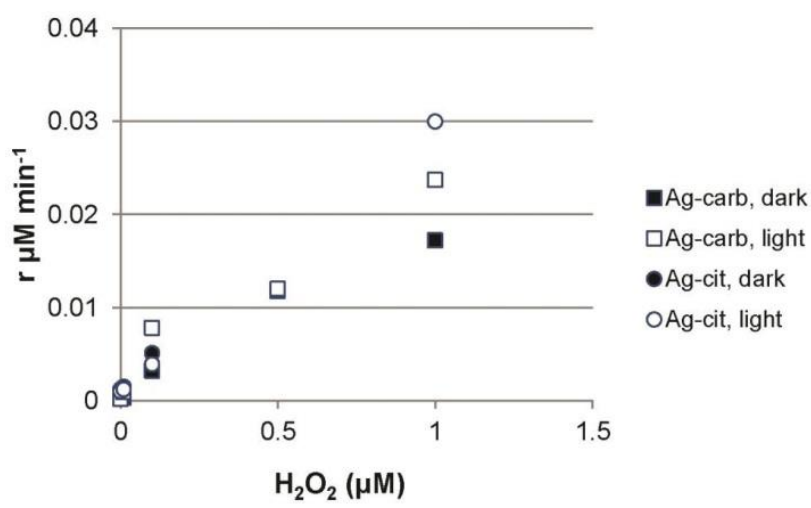

\section{Discussion}

Dissolution in the presence of ligands

Dissolution of AgNP under the influence of the ligands used here was not strongly induced at these relatively low concentrations, which are realistic with respect to media for toxicity experiments or to natural waters. Cysteine as a strong binding ligand for $\mathrm{Ag}^{+}$had the most pronounced effect on dissolution, with increased dissolution at the highest concentrations used here and over a few hours. However, reactions of $\mathrm{Ag}^{+}$with cysteine appear not only to lead to increased dissolution, but also to decreased dissolved concentrations after longer reaction times. Possible reactions after longer times (> $24 \mathrm{~h})$ include reduction reactions of $\mathrm{Ag}^{+}$and formation of polymeric species (Andersson, 1972; Gondikas et al., 2012). Those species formed after longer reaction times may be retained by the ultrafiltration membranes used here. Furthermore, some agglomeration effects in the presence of cysteine may also decrease dissolution reactions at longer times. In contrast to our present results, higher cysteine concentrations $(400 \mu \mathrm{M})$ and higher ratios of cysteine to total silver appear to lead to more extensive dissolution of AgNP, without evidence for reduction or formation of nonfilterable species for times up to $48 \mathrm{~h}$ (Gondikas et al., 2012). Other ligands with sulfide functional groups may have similar effects. Rapid dissolution of AgNP by reaction with a 
copper binding protein involving a thiol group has been shown, which highlights the high reactivity of thiols in biological ligands for silver binding (Martinolich et al., 2012).

In contrast to the high reactivity of thiol ligands, the effects of chloride and of fulvic acids to dissolution of AgNP were very limited. No agglomeration effects were expected under these conditions with low added chloride or fulvic acid concentrations. The $\mathrm{Ag}^{+}-$complexes with chloride have only a relatively low stability $\left(\mathrm{AgCl}^{0}(\mathrm{aq}): \log \mathrm{K}=3.3 ; \mathrm{AgCl}_{2}^{-}: \log \beta_{2}=5.2\right)$. At the highest $\mathrm{Cl}^{-}$concentration used here $(0.1 \mathrm{mM})$, only the formation of the $\operatorname{AgCl}^{0}(\mathrm{aq})$ complex is expected to occur according to equilibrium calculations. The formation of this complex appears to be of only slight effect in accelerating the dissolution of AgNP. At higher chloride concentrations, dissolution reactions may be faster, but are also complicated by precipitation of $\mathrm{AgCl}(\mathrm{s})$ (Yue et al., 2014). Complexes of $\mathrm{Ag}^{+}$with fulvic acids are also of limited stability, in particular if mostly carboxylic or phenolic functional groups are involved in binding (Chen et al., 2012). Those complexes appear also to have little effect in dissolving AgNP at realistic concentrations (Figure 4). Furthermore, reduction processes by fulvic acids may also occur, which may lead to a decrease of dissolved $\mathrm{Ag}^{+}$by renewed formation of AgNP. Formation of AgNP from dissolved $\mathrm{Ag}^{+}$was observed under the influence of extracellular polymeric substances extracted from periphyton biofilms (Kroll et al., 2014).

In conditioned media, it is expected that some ligands released by the algae are available, which may also include thiol ligands. However, there was no evidence for increased dissolution of AgNP in these media. The concentrations of produced ligands by algae may be too low to be effective. The decreasing dissolved Ag concentrations may indicate some reduction reactions, possibly due to organic algae products, or to other components of the culture media, or binding to higher molecular weight organic compounds. It is possible that $\mathrm{Fe}(\mathrm{II})$ was released from the FeEDTA complexes under light conditions and that $\mathrm{Fe}(\mathrm{II})$ then reduced $\mathrm{Ag}^{+}$.

\section{Dissolution with $\mathrm{H}_{2} \mathrm{O}_{2}$ as oxidant}

Dissolution of AgNP with both carbonate and citrate coatings by $\mathrm{H}_{2} \mathrm{O}_{2}$ appears to be very efficient, even at low $\mathrm{H}_{2} \mathrm{O}_{2}$ concentrations. Complete dissolution of $\mathrm{AgNP}$ was achieved within less than 1 hour in the presence of an excess of $\mathrm{H}_{2} \mathrm{O}_{2} . \mathrm{H}_{2} \mathrm{O}_{2}$ is a reactive oxidant, which is expected to react more readily with AgNP than oxygen, which was present in all experiments. The medium for the reactions with $\mathrm{H}_{2} \mathrm{O}_{2}$ was MOPS buffer, in which both carbAgNP and cit-AgNP were stable with respect to NP size. 
$\operatorname{Ag}(0)$ is expected to be dissolved by $\mathrm{H}_{2} \mathrm{O}_{2}$ with the overall stoichiometry:

$2 \mathrm{Ag}(0)+\mathrm{H}_{2} \mathrm{O}_{2}+2 \mathrm{H}^{+} \rightarrow 2 \mathrm{Ag}^{+}+2 \mathrm{H}_{2} \mathrm{O}$

$\operatorname{Ag}(0)$ was thus dissolved in excess of this stoichiometry, especially under light conditions, probably due to catalytic reactions involving produced radicals and oxygen, as oxygen was not excluded under these experimental conditions.

The obtained kinetic characteristics of the reaction of $\mathrm{H}_{2} \mathrm{O}_{2}$ with AgNP may be compared to literature values. The reaction of $\mathrm{AgNP}$ with $\mathrm{H}_{2} \mathrm{O}_{2}$ was examined in detail in (He et al., 2012b; He et al., 2011) and was written with the following general reactions:

$\mathrm{AgNP}+\mathrm{H}_{2} \mathrm{O}_{2} \rightarrow$ intermediates

Intermediates $+\mathrm{H}_{2} \mathrm{O}_{2} \rightarrow \mathrm{Ag}^{+}+\mathrm{O}_{2}^{-\cdot}+2 \mathrm{H}_{2} \mathrm{O}$

The intermediates may include the formation of hydroxyl radicals $(\mathrm{OH} \cdot)$ or of bound hydroxyl radicals $(\mathrm{Ag}-\mathrm{O}(\mathrm{H})-\mathrm{OH})$, with very short life-times. The decomposition of $\mathrm{H}_{2} \mathrm{O}_{2}$ upon contact with AgNP was followed over time in this study (He et al., 2011), which showed that $\mathrm{H}_{2} \mathrm{O}_{2}$ was consumed within about 10 minutes with an excess of AgNP (in the concentration range 1

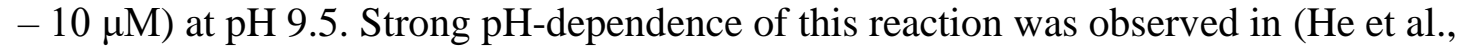
$2012 b)$, with very rapid decomposition at alkaline $\mathrm{pH}(9-14)$, and slower reaction rates at acidic $\mathrm{pH}$. The produced superoxide anion $\mathrm{O}_{2} \cdot{ }^{-}$(reaction 3 ) can then further react with $\mathrm{AgNP}$ and $\mathrm{Ag}^{+}$to form again $\mathrm{AgNP}$, or may recombine to form $\mathrm{H}_{2} \mathrm{O}_{2}$. The $\mathrm{pH}$-dependence of these reactions indicated that at higher $\mathrm{pH}(>9)$ the new formation of AgNP was important, and therefore after an initial decrease of AgNP concentration a new increase of AgNP was observed after longer times (He et al., 2012b). However, at intermediate $\mathrm{pH} 7$, dissolution of AgNP appeared to be predominant.

No obvious indication of reformation of $\mathrm{AgNP}$ was found in our experiments at $\mathrm{pH} 7.5$, but rather complete dissolution of AgNP in cases with an excess of $\mathrm{H}_{2} \mathrm{O}_{2}$, or formation of dissolved $\mathrm{Ag}^{+}$in proportion to added $\mathrm{H}_{2} \mathrm{O}_{2}$. However, the nearly identical dissolution rates with and without light in the case of cit-AgNP may indicate some re-reduction of dissolved $\mathrm{Ag}^{+}$under light conditions with citrate. This reaction did not appear to be important in the case of carb-AgNP. The observed kinetics in our experiments were in line with the fast kinetics of $\mathrm{H}_{2} \mathrm{O}_{2}$ decomposition in the studies by He et al. $(2011,2012)$. Using the secondorder rate constant for the reaction of cit- $\mathrm{AgNP}$ with $\mathrm{H}_{2} \mathrm{O}_{2}$ given in $\mathrm{He}$ et al. (2012), $\mathrm{k}_{2}=40$

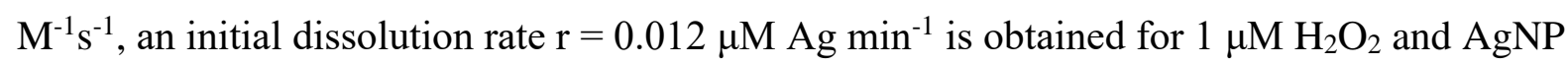
$=5 \mu \mathrm{M}$, which is comparable to the values obtained here. The small differences in dissolution 
rates between cit-AgNP and carb-AgNP may be due to the smaller size of the cit-AgNP which would result in somewhat higher surface area.

\section{Ag speciation and implications for toxicity experiments}

The speciation of $\operatorname{Ag}(\mathrm{I})$ in dissolved form is of utmost importance for its toxicity effects to aquatic organisms. The free $\mathrm{Ag}^{+}$ion is expected to be directly available for uptake to algae or bacteria, and may also be determining for uptake in higher organisms (Navarro et al., 2008; Yang et al., 2012; Piccapietra et al., 2012a; Xiu et al., 2012). The reactions described here may lead to either dissolved free $\mathrm{Ag}^{+}$-ions or to complexes with the available ligands. Dissolution of AgNP in the presence of cysteine would mostly lead to Ag-cysteine complexes (AgCysH and $\mathrm{Ag}(\mathrm{CysH})_{2}$ ) with high stability (Adams and Kramer, 1999; Navarro et al., 2008), as well as to possible polymeric species (Andersson, 1972). In the presence of an excess of cysteine over dissolved $\mathrm{Ag}(\mathrm{I})$, the free $\mathrm{Ag}^{+}$-ions are expected to be in a very low concentration range $\left(10^{-12}-10^{-11} \mathrm{M}\right)$ for the typical concentrations used here, based on equilibrium calculations as described in Navarro et al., 2008. In contrast, in the presence of chloride with $\mathrm{Cl}^{-}$(tot) $=0.1 \mathrm{mM}$, binding of $\mathrm{Ag}(\mathrm{I})$ in chloride complexes is incomplete and a large fraction of free $\mathrm{Ag}^{+}$would still be present. In a similar way, binding of $\mathrm{Ag}(\mathrm{I})$ by fulvic acids appears to be relatively weak (Chen et al., 2012), and a large fraction of $\mathrm{Ag}^{+}$may be expected in the presence of realistic concentrations of fulvic acids as used here. With regard to toxicity, increased dissolution of AgNP in the presence of cysteine would thus lead to the formation of cysteine-complexed $\operatorname{Ag}(\mathrm{I})$, which has been shown to be unavailable to algae and to exert no toxic effects to algae and to other organisms (Navarro et al., 2008; Xiu et al., 2012; Yang et al., 2012; Leclerc and Wilkinson, 2014; Navarro et al., 2015). In contrast, the Agchloride complexes may play a role in toxicity, as shown for fish cells (Yue et al., 2015).

The high efficiency of $\mathrm{H}_{2} \mathrm{O}_{2}$ in dissolving $\mathrm{AgNP}$ is likely to be of importance in toxic effects of AgNP to algae. $\mathrm{H}_{2} \mathrm{O}_{2}$ may be produced and released into solution by algae, in varying concentrations depending on the algae species and conditions (Palenik et al., 1987; Pospisil, 2012; He et al., 2012a; Suarez et al., 2013). The release of $\mathrm{H}_{2} \mathrm{O}_{2}$ by algae in contact with $\mathrm{AgNP}$ would lead to a rapid release of $\mathrm{Ag}^{+}$, as shown by the high reactivity reported here. These reactions would result in increasing $\mathrm{Ag}^{+}$availability close to algae cells and thus in increased $\mathrm{Ag}^{+}$-uptake. The produced $\mathrm{H}_{2} \mathrm{O}_{2}$ may be available in the nearest layer around a cell and react with any available AgNP in this layer. Such reactions may result in a higher $\mathrm{Ag}^{+}$ uptake from $\mathrm{AgNP}$ than expected from the measured dissolved concentrations in the absence 
367 of algae and thus contribute to AgNP toxicity, as previously inferred from results on toxicity 368 of AgNP to algae (Navarro et al., 2008; Navarro et al., 2015; Piccapietra et al., 2012a).

369

370 Acknowledgement

371 We thank Renata Behra for discussions and David Kistler for help with the ICP-MS

372 instrument. We thank Eawag for funding of this research.

373 


\section{References}

Adams, N.W.H., Kramer, J.R., 1999. Silver speciation in wastewater effluent, surface waters, and pore waters. Environmental Toxicology and Chemistry 18, 2667-2673.

Andersson, L.-O., 1972. Study of some silver-thiol complexes and polymers: stoichiometry and optical effects. J. Polymer Sci. 10, 1963-1973.

Behra, R., Sigg, L., Clift, M.J.D., Herzog, F., Minghetti, M., Johnston, B., Petri-Fink, A., RothenRutishauser, B., 2013. Bioavailability of silver nanoparticles and ions: from a chemical and biochemical perspective. J. R. Soc. Interface 10, 20130396.

Bury, N.R., Grosell, M., Grover, A.K., Wood, C.M., 1999. ATP-dependent silver transport across the basolateral membrane of rainbow trout gills. Toxicology and applied pharmacology 159, 1-8.

Bury, N.R., Wood, C.M., 1999. Mechanism of branchial apical silver uptake by rainbow trout is via the proton-coupled $\mathrm{Na}+$ channel American journal of physiology. Regulatory, integrative and comparative physiology 277, R1385-R1391.

Chen, Z.Z., Campbell, P.G.C., Fortin, C., 2012. Silver Binding by Humic Acid as Determined by Equilibrium Ion-Exchange and Dialysis. Journal of Physical Chemistry A 116, 6532-6539.

Geranio, L., Heuberger, M., Nowack, B., 2009. The Behavior of Silver Nanotextiles during Washing. Environmental Science \& Technology 43, 8113-8118.

Gondikas, A.P., Morris, A., Reinsch, B.C., Marinakos, S.M., Lowry, G.V., Hsu-Kim, H., 2012. Cysteine-Induced Modifications of Zero-valent Silver Nanomaterials: Implications for Particle Surface Chemistry, Aggregation, Dissolution, and Silver Speciation. Environ. Sci. Technol. 46, 7037-7045.

He, D., Dorantes-Aranda, J.J., Waite, T.D., 2012a. Silver Nanoparticle-Algae Interactions: Oxidative Dissolution, Reactive Oxygen Species Generation and Synergistic Toxic Effects. Environ. Sci. Technol. 46, 8731-8738.

He, D., Garg, S., Waite, T.D., 2012b. $\mathrm{H}_{2} \mathrm{O}_{2}$-Mediated Oxidation of Zero-Valent Silver and Resultant Interactions among Silver Nanoparticles, Silver Ions, and Reactive Oxygen Species. Langmuir 28, 10266-10275.

He, D., Jones, A.M., Garg, S., Pham, A.N., Waite, T.D., 2011. Silver Nanoparticle-Reactive Oxygen Species Interactions: Application of a Charging-Discharging Model. Journal of Physical Chemistry C 115, 5461-5468.

Hiriart-Baer, V.P., Fortin, C., Lee, D.Y., Campbell, P.G.C., 2006. Toxicity of silver to two freshwater algae, Chlamydomonas reinhardtii and Pseudokirchneriella subcapitata, grown under continuous culture conditions: Influence of thiosulphate. Aquat. Toxicol. 78, 136-148. 
Kaegi, R., Voegelin, A., Sinnet, B., Zuleeg, S., Hagendorfer, H., Burkhardt, M., Siegrist, H., 2011. Behavior of Metallic Silver Nanoparticles in a Pilot Wastewater Treatment Plant. Environ. Sci. Technol. 45, 3902-3908.

Kroll, A., Behra, R., Kaegi, R., Sigg, L., 2014. Extracellular polymeric substances (EPS) of freshwater biofilms stabilize and modify $\mathrm{CeO}_{2}$ and $\mathrm{Ag}$ nanoparticles. Plos One 9, e110709.

Leclerc, S., Wilkinson, K.J., 2014. Bioaccumulation of Nanosilver by Chlamydomonas reinhardtiiNanoparticle or the Free Ion? Environ. Sci. Technol. 48, 358-364.

Levard, C., Hotze, E.M., Lowry, G.V., Brown, G.E., 2012. Environmental Transformations of Silver Nanoparticles: Impact on Stability and Toxicity. Environ. Sci. Technol. 46, 6900-6914.

Liu, J., Hurt, R.H., 2010. Ion release kinetics and particle persistence in aqueous nano-silver colloids. Environ. Sci. Technol. 44, 2169-2175.

Liu, J., Sonshine, D.A., Shervani, S., Hurt, R.H., 2010. Controlled release of biologically active silver from nanosilver surfaces. ACS Nano 4, 6903-6913.

Lowry, G.V., Gregory, K.B., Apte, S.C., Lead, J.R., 2012. Transformations of nanomaterials in the environment. Environ. Sci Technol. 46, 6893-6899.

Ma, R., Levard, C., Marinakos, S.M., Cheng, Y., Liu, J., Michel, F.M., Brown, G.E., Lowry, G.V., 2011. Size-Controlled Dissolution of Organic-Coated Silver Nanoparticles. Environ. Sci Technol. 46, 752-759.

Martinolich, A.J., Park, G., Nakamoto, M.Y., Gate, R.E., Wheeler, K.E., 2012. Structural and Functional Effects of Cu Metalloprotein-Driven Silver Nanoparticle Dissolution. Environ. Sci Technol. 46, 6355-6362.

Navarro, E., Piccapietra, F., Wagner, B., Marconi, F., Kaegi, R., Odzak, N., Sigg, L., Behra, R., 2008. Toxicity of silver nanoparticles to Chlamydomonas reinhardtii. Environ. Sci Technol. 42, 8959-8964. Navarro, E., Wagner, B., Odzak, N., Sigg, L., Behra, R., 2015. Effects of differently coated silver nanoparticles on photosynthesis in Chlamydomonas reinhardtii. Environ. Sci Technol. 49, 8041-8047. Palenik, B., Zafiriou, O.C., Morel, F.M.M., 1987. Hydrogen peroxide production by a marine phytoplankter. Limnol. Oceanogr. 32, 1365-1369.

Piccapietra, F., Gil-Allué, C., Sigg, L., Behra, R., 2012a. Intracellular silver accumulation in Chlamydomonas reinhardtii upon exposure to carbonate coated silver nanoparticles and silver nitrate. Environ. Sci Technol. 46, 7390-7397.

Piccapietra, F., Sigg, L., Behra, R., 2012b. Colloidal stability of carbonate-coated silver nanoparticles in synthetic and natural freshwater. Environ. Sci. Technol. 46, 818-825. 
438 Pospisil, P., 2012. Molecular mechanisms of production and scavenging of reactive oxygen species by

439 photosystem II. Biochim. Biophys. Acta-Bioenerg. 1817, 218-231.

440 Sigg, L., Behra, R., Groh, K., Isaacson, C.W., Odzak, N., Piccapietra, F., Röhder, L., Schug, H., Yue, 441 Y., Schirmer, K., 2014. Chemical aspects of nanoparticle ecotoxicology. Chimia 68, 806-811.

442 Suarez, G., Santschi, C., Slaveykova, V.I., Martin, O.J.F., 2013. Sensing the dynamics of oxidative

443 stress using enhanced absorption in protein-loaded random media. Scientific Reports 3, 3447.

444 Topuz, E., Sigg, L., Talinli, I., 2014. A systematic evaluation of agglomeration of Ag and TiO2

445 nanoparticles under freshwater relevant conditions. Environ. Poll. 193, 37-44.

446 Xiu, Z.-M., Ma, J., Alvarez, P.J.J., 2011. Differential Effect of Common Ligands and Molecular

447 Oxygen on Antimicrobial Activity of Silver Nanoparticles versus Silver Ions. Environ. Sci. Technol.

$448 \quad 45,9003-9008$.

449 Xiu, Z.M., Zhang, Q.B., Puppala, H.L., Colvin, V.L., Alvarez, P.J.J., 2012. Negligible particle-

450 specific antibacterial activity of silver nanoparticles. Nano-Letters 12, 4271-4275.

451 Yang, X., Gondikas, A.P., Marinakos, S.M., Auffan, M., Liu, J., Hsu-Kim, H., Meyer, J.N., 2012.

452 Mechanism of silver nanoparticle toxicity is dependent on dissolved silver and surface coating in

453 Caenorhabditis elegans. Environ. Sci Technol. 46, 1119-1127.

454 Yue, Y., Behra, R., Sigg, L., Fernandez Freire, P., Pillai, S., Schirmer, K., 2015. Toxicity of silver 455 nanoparticles to a fish gill cell line: role of medium composition. Nanotoxicology 9, 54-63. 
457

458

459

460

461

462

463

Fig. SI 2: Dissolved Ag from carbonate $\mathrm{AgNP}$ (total $\mathrm{Ag}=1 \mu \mathrm{M}$ ) with $0.01 \mu \mathrm{M} \mathrm{H}_{2} \mathrm{O}_{2}$ under dark and light conditions as a function of time over $4 \mathrm{~h}$.

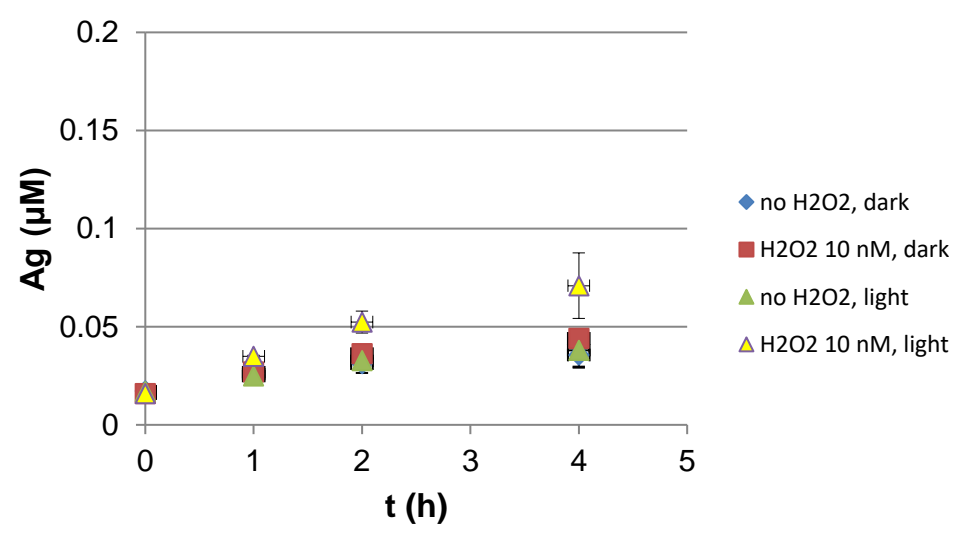

Fig. SI 1: Dissolved Ag from carbonate $\mathrm{AgNP}$ (total $\mathrm{Ag}=5 \mu \mathrm{M}$ ) in conditioned algae culture media under dark and light conditions as a function of time over $24 \mathrm{~h}$.

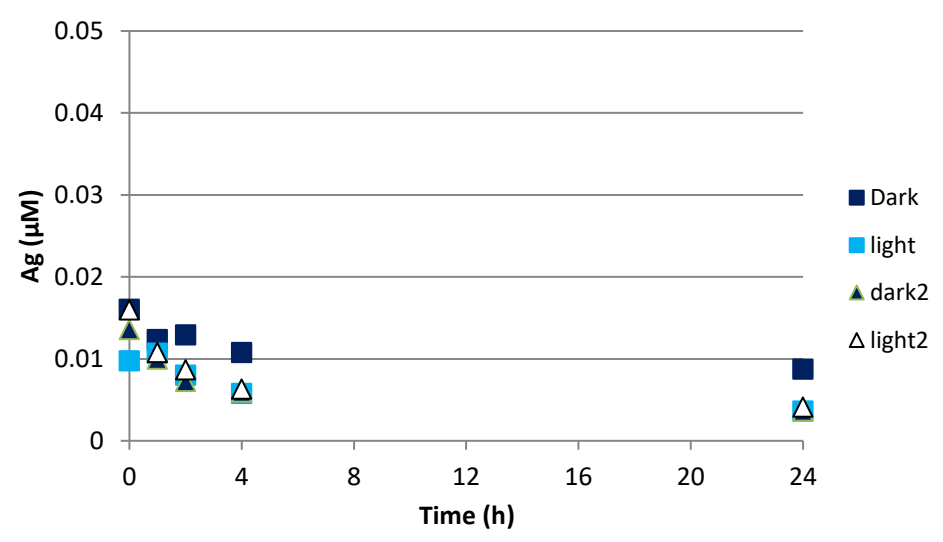

